\title{
A Comparative Study of Focus Realization in Three Swedish Dialects
}

\author{
Robert Eklund \\ Journal Article
}

\section{Tweet}

N.B.: When citing this work, cite the original article.

Original Publication:

Robert Eklund, A Comparative Study of Focus Realisation in Three Swedish Dialects, Journal of the Acoustical Society of America, 1996. 99(4), p. 2492.

Copyright: Acoustical Society of America / Nature Publishing Group http://acousticalsociety.org/

Postprint available at: Linköping University Electronic Press

http://urn.kb.se/resolve?urn=urn:nbn:se:liu:diva-135276 


\title{
A comparative study of focus realisation in three Swedish dialects
}

\author{
Robert Eklund \\ Telia Research AB
}

State-of-the-art speech recognition and speech translation systems do not currently make use of prosodic information. Utterances often have one or more constituents semantically focused by prosodic means and detection of the focus/foci of an utterance is crucial for a correct interpretation of the speech signal. Thus, a semantic model of focus should be linked to a model describing the acoustic-phonetic correlates of the speech. However, variability exists at both the semantic and the prosodic ends. Semantically different kinds of foci might be associated with specific prosodic gestures. Also, a semantically specific type of focus might be realised in different ways in different varieties of a given language since general intonational patterns vary between dialects. In this paper, focus realisation in three different dialects of Swedish is investigated. Subjects from Stockholm, Göteborg and Malmö recorded three sets of four sentences where focus was systematically put on four different constituents by having the subjects answer wh-questions. Since Swedish is a language with two tonal accents, words with these accents both in and out of focus were included. Dialectal as well as individual variation in focus realisation is described with emphasis on invariant and optional phenomena.

[ JASA, vol. 99, no. 4, pt. 2, April 1996, p. 2492 (2pSC3) ] 